\title{
Ensino de estatística aplicada à administração a distância: um estudo empírico
}

\section{Teaching of statistics applied to administration in the distance learning mode: an empirical study}

\author{
Daielly Melina Nassif Mantovani ${ }^{1}$; Adriana Backx Noronha Viana ${ }^{2}$; \\ Maria Aparecida Gouvêa ${ }^{3}$
}

\section{Resumo}

Este artigo tem como objetivos: avaliar a experiência dos alunos do curso de graduação em Administração da FEA-RP/USP nas atividades on-line de uma disciplina de Estatística Aplicada e conhecer as características de seu perfil. Focalizou-se uma disciplina semipresencial, que utilizou um ambiente virtual acessado via Internet para disponibilizar materiais didáticos digitais e realizar atividades como enquetes e discussões síncronas e assíncronas. Para o sucesso de um curso on-line, é necessário que os estudantes possuam estrutura adequada de acesso; assim, estudou-se o perfil dos alunos inscritos na matéria. Eles apresentaram estrutura de acesso favorável e conhecimentos sobre Internet, e-mail, chat e fórum, o que influenciou positivamente a satisfação com o curso. Ao final do semestre, realizaram-se grupos focais nos quais os alunos avaliaram a experiência na disciplina. Esta foi considerada positiva, e atribuiu-se flexibilidade ao curso, pois os materiais puderam ser acessados e os trabalhos entregues via Internet a qualquer hora e de qualquer lugar. A interatividade e o atendimento da tutoria contribuíram para a aprendizagem. No entanto, os alunos apontaram que, caso não houvesse obrigatoriedade, não teriam participado das atividades on-line, o que torna este ponto relevante no planejamento do curso. A EAD pode ser utilizada com sucesso no ensino de Estatística; porém, o planejamento cuidadoso é fundamental.

Palavras chave: Ensino de estatística. E-learning. Perfil do usuário

\begin{abstract}
The present article has two purposes: to assess the experience of undergraduate students in the course of Administration at FEA-RP/USP in on-line activities of an Applied Statistics discipline and to learn the characteristics of its profile. We focused on a discipline taught in a blended way where a virtual environment accessed via Internet was used to provide digital teaching materials and perform activities such as research and synchronous and asynchronous discussions. In order to ensure the success of an on-line course, students must have proper access to digital tools; thus, the profile of the students enrolled in the discipline was studied. They were found to have proper access and knowledge concerning e-mail, chat and forum tools, which had a positive effect on their satisfaction with the course. At the end of the semester, focal groups were formed to assess the experience in the discipline. The students considered the discipline positive because it conferred flexibility to the course, with the materials accessed and works submitted via Internet any time and anywhere. The interactivity and tutorial assistance contributed to the learning. However, the students reported that they only enrolled in the on-line discipline because it
\end{abstract}

\footnotetext{
1 Faculdade de Economia, Administração e Contabilidade de Ribeirão Preto (FEA-RP/USP) - email: daielly@usp.br

2 Professora Livre Docente do Departamento de Administração da Faculdade de Economia, Administração e Contabilidade de Ribeirão Preto (FEA-RP/USP). Email: backx@usp.br

3 Professora Livre Docente do Departamento de Administração da Faculdade de Economia, Administração e Contabilidade (FEA/ USP). Email: magouvea@usp.br
} 
was compulsory, which has to be taken into consideration in the course planning. Distance learning can be successfully used in the teaching of Statistics; however, careful planning is essential.

Key words: Teaching of statistics. E-learning. User's profile.

\section{Introdução}

O processo de ensino-aprendizagem de Estatística para cursos das ciências sociais aplicadas, em especial para Administração, representa um grande desafio tanto aos professores quanto aos alunos. De acordo com Nolan e Speed (1999), os alunos têm dificuldade em aplicar os conceitos estatísticos aprendidos em sala de aula a contextos independentes, tanto no trabalho quanto em problemas reais ou mesmo em outras disciplinas de seus cursos. Isso ocorre por não conseguirem fazer uma relação entre a utilização da Estatística e situações reais típicas de sua profissão.

Por outro lado, o mundo vem sofrendo grandes e profundas mudanças e com isto as formas de se conduzirem os processos de ensino-aprendizagem também têm-se alterado. De acordo com Borba e Ayrosa (2001), os educadores já não podem ignorar o uso de tecnologias em suas práticas didáticas, pois há uma tendência de que as futuras gerações de alunos iniciem sua educação já familiarizados com as tecnologias mediadas por computador. Dessa maneira, a modernização e a flexibilização do ensino presencial acabam tornando-se essenciais (BORBA; AYROSA, 2001).

Pan (2003) aponta que as tecnologias computacionais têm mudado rapidamente a forma de se ensinar Estatística, por meio do emprego de diversas mídias, da Internet e da Worl Wide Web. A utilização das tecnologias possui como ponto forte o envolvimento do aprendiz em seu próprio processo de aprendizagem, gerando automotivação ao estudo. Nesse contexto, o professor, além de dividir o controle do processo de ensino-aprendizagem com o aprendiz, presta cuidadosa atenção ao progresso de cada aluno individualmente (PAN, 2003).
Nesse sentido, as ferramentas da educação a distância propõem uma mudança de paradigma educacional, à medida que incentivam a aprendizagem colaborativa por meio da interação aluno/conteúdo, aluno/aluno e aluno/professor online (PINHEIRO, 2002).

Esta pesquisa possui delineamento por estudo de caso único, desenvolvido em duas etapas, a primeira quantitativa e descritiva, e uma segunda qualitativa e exploratória. O estudo tem como objetivos: avaliar a experiência dos alunos do curso de graduação em Administração da FEA-RP/ USP nas atividades on-line de uma disciplina de Estatística Aplicada e conhecer as características de seu perfil. Para tanto, estudou-se uma disciplina semipresencial de Estatística da FEA-RP/USP, ministrada no primeiro semestre de 2007, que teve $20 \%$ de sua carga horária preenchida por atividades a distância, tais como, discussão em fórum, plantões de dúvidas em chat, enquetes e estudo de materiais didáticos digitais. Estas atividades foram ministradas por meio de um ambiente virtual de aprendizagem, denominado LaViE (http:// www.lavie.adm.br), acessado via Internet pelos estudantes com login e senha individuais.

Devido às particularidades do e-learning, tal como o uso extensivo de computadores e da Internet, torna-se relevante conhecer a opinião dos alunos acerca dos cursos dessa natureza e seus hábitos de acesso e o conhecimento das ferramentas do e-learning utilizadas na disciplina. Essas informações foram levantadas por meio de um survey de perfil e, ao final do curso, foram realizados grupos focais (focus groups) com os alunos, para que eles avaliassem a experiência na disciplina semipresencial. 


\section{Revisão Bibliográfica}

Neste item, são discutidas as características do e-learning, design de cursos on-line e o ensino de estatística.

\section{Características do e-learning}

Filatro (2004) afirma que o termo educação on-line (ou e-learning) não é um sinônimo da educação a distância. A educação on-line é "uma ação sistemática de uso de tecnologias, abrangendo hipertexto e redes de comunicação interativa, para distribuição de conteúdo educacional e promoção da aprendizagem sem limitação de tempo ou lugar" (FILATRO, 2004, p. 47).

A educação a distância, apesar de também supor a ausência de barreiras de tempo e espaço, não depende apenas da comunicação on-line (o que ocorre, por exemplo, nos cursos por correspondência); portanto, a educação on-line pode ser considerada uma modalidade da educação a distância (FILATRO, 2004).

O e-learning, ou educação on-line, consiste na utilização de tecnologias e da Internet no processo de ensino-aprendizagem. A entrega dos conteúdos didáticos é feita aos aprendizes via redes de computador (CARVALHO NETO; ZWICKER; CAMPANHOL, 2006).

$\mathrm{O}$ uso das tecnologias da informação e comunicação depende da infra-estrutura tecnológica disponível, da capacidade humana em lidar com tecnologias e dos objetivos educacionais propostos (FILATRO; PICONEZ, 2004).

Rosenberg (2001) apresenta alguns critérios fundamentais, nos quais o conceito de e-learning está baseado:

- a transmissão em rede, que possibilita a atualização instantânea,

- $\mathrm{o}$ arquivamento,

-a distribuição e compartilhamento de instruções e informações,
- a disponibilização via computador, que consiste na utilização dos padrões de tecnologia da Internet,

- o foco em uma visão ampla de aprendizado.

O autor ainda apresenta alguns benefícios do e-learning (ROSENBERG, 2001):

-a redução de custos - menor necessidade de infra-estrutura;

- o uso de mensagens consistentes - as pessoas recebem o mesmo conteúdo, apresentado da mesma forma;

-a facilidade e rapidez na atualização do conteúdo; - a transposição de barreiras de espaço e tempo; - a facilidade de uso para indivíduos familiarizados com a Internet;

- a universalidade - aproveitamento dos protocolos e browsers universais da Internet;

- a construção de comunidades para compartilhamento de conhecimentos e insights após o curso;

- a escala - possibilidade de aumentar o número de alunos com um pequeno esforço e custo incremental.

A participação em atividades on-line requer do aprendiz a conscientização do seu papel no processo instrucional e, em contextos mais avançados, exige a responsabilização pelo desenvolvimento de discussões (LAAT; LALLY, 2004). A utilização da Internet e de tecnologias da informação e comunicação na educação modifica o papel dos atores envolvidos. O professor passa a ser apenas um orientador do processo de aprendizagem, pois deixa de ser o responsável pela entrega do conhecimento. O aluno torna-se autônomo e responsável por seu aprendizado, à medida que gerencia seu tempo e decide o que estudar. Isto exige uma postura mais dinâmica e ativa no processo (FREITAS; BERTRAND, 2006).

A interação é apontada como fator fundamental 
para o sucesso de um curso na modalidade e-learning, pois reduz a sensação de distância e torna o curso mais dinâmico. A comunicação mediada por computador se refere às interações pessoa/computador e pessoa/pessoa por meio do computador, isto é, permite situações que não ocorrem presencialmente (RAMOS, 2005).

Essa interação pode ocorrer de forma síncrona ou assíncrona e, além de comunicação, essas duas modalidades de interação podem ser utilizadas para o acompanhamento dos alunos. Na modalidade síncrona, a comunicação entre participantes ocorre de forma simultânea, ou seja, alunos e professores/ tutores se comunicam em tempo real, e isso permite a criação de coesão e mantém o ritmo do grupo. Em oposição, a comunicação assíncrona é mais flexível, pois não necessita de participação simultânea das partes; assim, os alunos podem definir seu ritmo de trabalho e possuem tempo para refletir e pesquisar as idéias que apresentarão (FREITAS; BERTRAND, 2006).

\section{Design de cursos on-line}

De acordo com Filatro e Piconez (2004, p. 2), o "design instrucional é compreendido como uma nova forma de planejamento do ensinoaprendizagem, incluindo atividades, estratégias, sistemas de avaliação, métodos e materiais instrucionais".

Ao se planejar um curso, é necessário considerar a auto-estima do aluno, a necessidade de constante feedback, a criação de situações para o desenvolvimento da criatividade, a necessidade de comunicação, a colaboração e estímulo à autonomia e à responsabilidade (VIEIRA, 2001).

De acordo com Vieira (2001), um sistema de educação a distância mediado pela Internet envolve muitos elementos, tais como o processo de ensinoaprendizagem, comunicação, design, editoração e gestão. Conseqüentemente, os cursos on-line devem passar por um planejamento estruturado que esclareça a forma de se operacionalizar o que foi proposto.

O design deve proporcionar espaço para o diálogo, autonomia e contextualização. A contextualização caracteriza-se por maior personalização quanto aos estilos e ritmos de aprendizagem; a adaptação às características institucionais e regionais; atualização a partir de feedback constante; o acesso a informações e experiências externas à organização de ensino; a possibilidade de comunicação entre professores, alunos, tutores, equipe técnica etc.; o monitoramento da construção individual e coletiva de conhecimentos (FILATRO; PICONEZ, 2004).

Os modelos de design instrucional geralmente compreendem os estágios de análise, design, implementação e avaliação (FILATRO; PICONEZ, 2004). O design compreende o planejamento da instrução e a elaboração dos materiais e produtos instrucionais. A implementação compreende a capacitação e a ambientação de docentes e alunos à proposta de design e a realização do evento ou situação de ensino-aprendizagem. A avaliação compreende o acompanhamento do curso, revisão dos conteúdos e sua manutenção (FILATRO; PICONEZ, 2004).

Maximiano, Jacobsohn e Kuniyonshi (2005) afirmam que o plano de cursos a distância requer, além das escolhas normalmente realizadas na modalidade presencial, a consideração de outras questões tais como a produção prévia do material didático e suas formas de apresentação e estratégias para reduzir os efeitos do isolamento causado pela distância. Assim, criam-se boas condições para a interação entre alunos, professores, tutores e colegas. Dessa maneira, os autores apontam que "além dos problemas tecnológicos e metodológicos, a implantação da educação a distância exige um robusto componente gerencial" (MAXIMIANO; JACOBSOHN; KUNIYONSHI, 2005, p. 2).

O design instrucional pode confluir para um 
ensino individualizado que, segundo Vieira (2001):

- permite que o aluno inicie o estudo do ponto que desejar, pois a aprendizagem ocorre no seu ritmo;

- considera a preparação do aluno, a posse dos pré-requisitos necessários para a adequada execução das tarefas;

- considera diferenças individuais, como o estilo de aprendizagem;

- o professor consegue reconhecer o nível de aprendizagem de cada aluno, podendo indicarthe as atividades que melhor lhe satisfaçam as necessidades e interesses do aluno.

Com a abundância e a facilidade de manipulação dos recursos disponíveis nos sistemas de gerenciamento de cursos (SGCs), há uma tendência em se negligenciar a atividade de design, o que acarreta em cursos cujas atividades não contribuem de forma satisfatória para o processo de ensinoaprendizagem (KOSZALKA; GANESAN, 2004).

Atividades mal organizadas e mal planejadas podem impedir a ocorrência da aprendizagem e a construção de comunidades. E, além disso, após o início do curso ou atividade, possíveis correções tornam-se de difícil realização (DENNEN, 2005).

\section{Ensino de estatística}

O campo de aplicação da Estatística tem se ampliado consideravelmente, devido à necessidade de tomada rápida e segura de decisões. O pensamento estatístico facilita a solução de problemas e baseia-se em encontrar informações por trás de fatos e dados, e não de opiniões. A Estatística é um instrumento fundamental para pesquisadores e profissionais de diversas áreas que precisem compreender fatos sob várias perspectivas (MILAGRE, 2001; CARVALHO, 2003).
Em especial na Administração, a Estatística representa um conjunto de técnicas importantíssimas que auxiliam a tomada de decisões, atividade tão presente no cotidiano dos administradores (MILAGRE, 2001). Está claro que o risco é um fator inerente a qualquer processo decisório e a aplicação da Estatística não consegue eliminá-lo por completo; entretanto, pode auxiliar a redução do nível de incerteza atribuído à decisão a ser tomada (MILAGRE, 2001).

Diante dessa relevância, os cursos universitários da área de ciências aplicadas, como a Administração, Engenharia, Psicologia, Medicina, Turismo etc., costumam possuir disciplinas obrigatórias de Estatística em suas grades curriculares (PAN; TANG, 2004; PETOCZ; REID, 2005). A Estatística é incluída nestes cursos com intuito de capacitar os aprendizes na utilização dos conceitos estatísticos como uma ferramenta de apoio e não como uma habilidade central no contexto profissional, ou seja, a Estatística é considerada um meio e não um fim para estas profissões (PETOCZ; REID, 2005).

Muitos estudantes desses cursos não possuem uma base adequada de conhecimentos matemáticos e estatísticos, de forma que acabam por vivenciar alto grau de ansiedade durante os cursos de Estatística (PAN; TANG, 2004). A ansiedade estatística pode afetar negativamente a aprendizagem do aluno e é definida como a ansiedade enfrentada ao se deparar com a Estatística de qualquer forma e em qualquer nível (PAN; TANG, 2004).

Paralelamente, existe o fator agravante de que os professores que ministram disciplinas de Estatística nos cursos de Administração costumam possuir formação matemática e recebem pouca preparação para a atividade de ensinar, o que os leva a ter dificuldades em aproximar a Estatística da realidade dos alunos não-estatísticos (GELMAN, 2005). 
Como resultado da interação de todos os fatores apresentados nesta seção, tem-se uma influência negativa na aprendizagem, e a Estatística se torna uma das competências mais fracas adquiridas durante a universidade (PAN; TANG, 2004).

Em face do contexto apresentado, tornase necessário reduzir a ansiedade dos alunos e transformar em positivas as atitudes negativas com relação à Estatística. Para tanto, os educadores devem mudar suas estratégias de ensino (STORK, 2003). Alguns recursos, como a utilização de computadores, exemplos práticos, humor, linguagem estatística simples, trabalho em grupo, ambientes colaborativos, onde seja possível a aprendizagem ativa, podem reduzir a ansiedade e proporcionar aprendizagem efetiva dos conceitos estatísticos (PAN; TANG, 2004).

Uma das mudanças de maior impacto introduzida no ensino de Estatística diz respeito à utilização do computador e de tecnologias em geral no processo de ensino-aprendizagem (MILAGRE, 2001; PAN, 2003).

Além dos pacotes estatísticos, a evolução tecnológica torna o computador uma ferramenta útil ao processo de ensino-aprendizagem, à medida que permite ao aluno interagir e executar inúmeras atividades que fomentam a construção de conhecimentos e o desenvolvimento do pensamento crítico (BEM-ZVI, 2000; MILAGRE, 2001). Ambientes virtuais de ensino-aprendizagem podem ser utilizados para o ensino de Estatística, devido à grande quantidade de recursos e ferramentas que disponibilizam ao aluno (PAN, 2003).

No caso da utilização de ambientes virtuais de aprendizagem, Pan (2003) afirma que a preparação de cursos de Estatística a serem ministrados online requer grande investimento de tempo e esforço. As ferramentas tecnológicas podem ser utilizadas para estimular a aprendizagem ativa, dar a oportunidade aos alunos para refletir sobre os assuntos aprendidos, desenvolver o pensamento crítico e criar sinergias entre conteúdo, pedagogia e tecnologia (BEM-ZVI, 2000).

Os conceitos apresentados nesta revisão teórica servirão como diretrizes neste estudo para o alcance de seus objetivos.

\section{Metodologia}

Neste item são discutidas a definição da pesquisa e as técnicas utilizadas para coleta e análise dos dados.

\section{Definição da pesquisa}

Para o alcance do objetivo geral definido como: "avaliar a experiência dos alunos do curso de graduação em Administração da FEA-RP/ USP nas atividades on-line de uma disciplina de Estatística Aplicada e conhecer as características de seu perfil", foi realizado um estudo de caso com o desenvolvimento de duas etapas. A primeira etapa foi quantitativa e descritiva e consistiu no levantamento do perfil dos alunos. A segunda etapa, de natureza qualitativa e exploratória, teve como objetivo conhecer a opinião dos alunos da disciplina em relação à experiência com o e-learning.

Segundo Yin (2005, p. 32), um estudo de caso é "uma investigação empírica que analisa um fenômeno contemporâneo dentro de seu contexto real, quando os limites entre o fenômeno e o contexto não estão claramente definidos", e o pesquisador não possui controle sobre os eventos comportamentais, de forma que a coleta e análise de dados apresentam características específicas.

Nesta abordagem, o pesquisador busca apreender a totalidade de uma situação e então descrever, compreender e interpretar a complexidade do caso, revelando análises em profundidade (MARTINS, 2006). Os estudos de caso são utilizados com o objetivo de aumentar a compreensão acerca de fenômenos sociais 
complexos e de responder a perguntas do gênero “como?" e "por quê?", permitindo-se preservar os aspectos significativos dos acontecimentos reais (YIN, 2005).

De acordo com Yin (2005), o estudo de caso possui duas variações, o estudo de caso único ou estudo de múltiplos casos. O estudo de caso único é adequado quando representa "o caso decisivo ao testar uma teoria bem-formulada [...], para determinar se as proposições de uma teoria são corretas ou se algum outro conjunto de explanações pode ser mais relevante" (YIN, 2005, p. 62). É também adequado quando o caso único representa um caso raro ou extremo, representativo ou típico, revelador ou longitudinal, isto é, mesmo caso estudado em dois pontos distintos no tempo (YIN, 2005).

Este estudo pode ser definido como um estudo de caso único, pois identificou o perfil e analisou a experiência dos alunos de Administração da FEARP/USP nas atividades on-line de uma disciplina semipresencial de Estatística Aplicada.

Em relação às etapas do estudo de caso, tem-se que o método quantitativo utiliza a quantificação tanto na coleta quanto na análise de dados, a fim de garantir a precisão dos resultados e evitar equívocos em sua análise e interpretação (RICHARDSON, 1999). Esta abordagem é freqüentemente utilizada em estudos descritivos. Esses estudos têm como objetivo principal descrever as características de uma determinada população ou fenômeno ou estabelecer relações entre variáveis (GIL, 2002). Assim, a primeira etapa do estudo de caso pode ser classificada como quantitativa e descritiva, pois por meio de instrumentos estruturados e técnicas estatísticas apurou-se o perfil dos estudantes matriculados na disciplina focalizada.

Richardson (1999) afirma que a abordagem qualitativa é uma forma adequada à compreensão da natureza de um fenômeno social e possui como objeto situações complexas e particulares, dificilmente explicadas de forma quantitativa.
O método qualitativo pode ser empregado em pesquisas cujos objetivos sejam descrever a complexidade de um fenômeno, analisar a interação entre variáveis, compreender processos dinâmicos em grupos sociais, contribuir no processo de mudança de um grupo e proporcionar compreensão aprofundada sobre o comportamento de indivíduos (RICHARDSON, 1999). Os estudos exploratórios têm como objetivo proporcionar maior conhecimento acerca do problema, de forma a aprimorar idéias ou descobrir intuições (GIL, 2002). Dessa maneira, a segunda etapa do estudo de caso pode ser considerada qualitativa e exploratória, pois teve como objetivo conhecer a opinião e atitudes dos alunos após a experiência com o e-learning, com vistas a identificar os impactos na aprendizagem, os sentimentos experimentados e possíveis pontos de aperfeiçoamento no desenho do curso.

\section{Coleta e análise dos dados}

Estudou-se nesta pesquisa a experiência dos alunos nas atividades on-line de uma disciplina semipresencial de Estatística, denominada "Estatística Aplicada à Administração I" ministrada no primeiro semestre de 2007 no curso de graduação da FEA-RP/USP.

A literatura aponta que, ao se planejar um curso on-line é necessário levar em conta o perfil do público-alvo, para que as atividades e materiais estejam alinhados às suas necessidades de aprendizagem. É relevante também verificar a estrutura de acesso do aluno, pois esse fator possui grande impacto no sucesso do curso.

Dessa forma, primeiramente realizou-se uma pesquisa do perfil dos 99 alunos que cursaram a disciplina. Esses dados foram levantados na primeira aula do curso, por meio de um survey descritivo. Os survey descritivos são realizados com objetivo de descrever aspectos de uma população ou analisar determinadas características 
ou atributos (RICHARDSON, 1999). Nesse estudo, o survey descritivo foi aplicado por meio de um questionário autopreenchido, composto de perguntas fechadas e abertas. Estes dados foram analisados por meio de estatísticas descritivas e métodos gráficos.

Ao final da disciplina, foram realizados quatro grupos focais com os alunos, dois no período diurno e dois no período noturno, com intuito de verificar qual foi a percepção dos estudantes a respeito das atividades on-line realizadas ao longo do semestre.

O grupo focal é um tipo de entrevista em profundidade realizada em grupo (MARTINS, 2006), em que os participantes são incentivados a discutir entre si, fazendo perguntas, trocando experiências e comentando os pontos de vista uns dos outros (BARBOUR; KITZINGER, 1999). É um tipo especial de grupo, em termos de proposta, tamanho, composição e procedimentos e o que o diferencia de outras técnicas é a presença ativa do moderador, encorajando a participação dos membros e prestando atenção à interação do grupo (BARBOUR; KITZINGER, 1999). A proposta central desta técnica é ouvir e extrair informações por meio das interações entre os membros do grupo, identificar e entender a maneira como as pessoas pensam ou sentem-se sobre determinado assunto, produto ou serviço, provendo autodiscussão e revelação entre os participantes (KRUEGER; CASEY, 2000).

Cada grupo focal contou com a participação de oito estudantes e a moderação da tutora da disciplina. Primeiramente, solicitou-se que cada aluno enumerasse individualmente e por escrito cinco pontos positivos e cinco pontos negativos das atividades on-line desenvolvidas. Após essa atividade, a moderadora leu em voz alta os pontos positivos levantados por cada aluno e iniciou-se a discussão a respeito de cada um deles. O mesmo processo foi realizado para os pontos negativos. Ao final, solicitou-se que os participantes oferecessem sugestões para aperfeiçoamento das atividades on-line. Os resultados dos grupos focais foram analisados pelo método da análise de conteúdo.

\section{Resultados}

Neste item, será apresentado o perfil dos alunos que cursaram a disciplina estudada, o qual foi identificado por meio da pesquisa quantitativa, características da disciplina e a avaliação feita pelos estudantes ao final da disciplina, revelada na pesquisa qualitativa.

\section{Perfil dos alunos}

O caso abordado neste artigo consiste da disciplina de graduação "Estatística Aplicada à Administração I", ministrada no primeiro semestre de 2007. Ambas as turmas que cursaram a disciplina foram estudadas (período diurno e noturno), totalizando 99 questionários respondidos, sendo $58 \%$ do período diurno e $42 \%$ do período noturno.

Descreve-se, a seguir, o perfil de ambas as turmas, considerando dados demográficos, estrutura de acesso à Internet, hábitos de acesso e conhecimentos sobre a educação a distância e ferramentas para análise de dados.

\section{Perfil demográfico}

A média etária dos alunos é de 19,9 anos. Os alunos do período diurno caracterizam-se por serem mais jovens que os alunos do curso noturno e por possuírem idade mais homogênea, ou seja, não há grande diferença de idade entre eles. Considerando-se o sexo, a maioria dos alunos é do sexo masculino. Em ambos os períodos, há predominância do sexo masculino; entretanto, observa-se que, no período noturno, a proporção de alunos deste sexo é de $76 \%$. O Quadro 1 apresenta esses dados resumidamente. 
Quadro 1. Perfil demográfico dos alunos.

\begin{tabular}{|c|c|c|c|c|c|c|}
\hline & \multicolumn{3}{|c|}{ Idade } & \multicolumn{2}{|c|}{ Sexo } & \multirow[t]{2}{*}{ Total } \\
\hline & Média & Desvio-padrão & Coeficiente de variação & Masculino & Feminino & \\
\hline Diurno & 19,3 anos & 1,18 anos & $6,1 \%$ & 33 alunos & 24 alunos & 57 alunos \\
\hline Noturno & 20,8 anos & 2,68 anos & $12,9 \%$ & 32 alunos & 10 alunos & 42 alunos \\
\hline Total & 19,9 anos & 2,08 anos & $10,45 \%$ & 65 alunos & 34 alunos & 99 alunos \\
\hline
\end{tabular}

Fonte: Do Autor

\section{Estrutura de acesso}

Em geral, a maior parte dos alunos, de ambos os períodos, possui computador em suas residências e acesso à Internet. Entretanto, os dados revelam que uma proporção maior de alunos do período diurno possui computador em suas casas. Em oposição, considerando-se o acesso à Internet, tem-se uma proporção maior de alunos do período noturno com acesso à Internet.

Dentre os alunos que possuem acesso à Internet em suas casas, o tipo de conexão mais utilizado é o tipo banda larga, seguido pela conexão discada.
Verifica-se que, no período diurno, a proporção de alunos com acesso banda larga (79\%) é maior que no período noturno (69\%). Assim, há maior proporção de alunos do noturno com acesso discado $(29 \%)$ do que no período diurno $(15,4 \%)$.

Nesse contexto, pode-se dizer que, em geral, os alunos possuem estrutura de acesso de boa qualidade, o que contribui relevantemente para o sucesso de um curso na modalidade e-learning. Particularmente, no período diurno há uma proporção maior de alunos com estrutura de acesso adequada. O Quadro 2 apresenta os dados de estrutura de acesso.

Quadro 2. Estrutura de acesso possuída pelos alunos

\begin{tabular}{|lllllll|}
\hline Estrutura de Acesso & & \multicolumn{2}{c}{ Diurno } & \multicolumn{2}{c|}{ Noturno } & Total \\
\hline Possui computador & Sim & 56 alunos & $98,2 \%$ & 39 alunos & $92,9 \%$ & 95 alunos \\
& Não & 1 aluno & $1,8 \%$ & 3 alunos & $7,1 \%$ & 4 alunos \\
\multirow{2}{*}{ Possui acesso à Internet Sim } & 52 alunos & $92,9 \%$ & 38 alunos & $97,4 \%$ & 90 alunos \\
& Não & 4 alunos & $7,1 \%$ & 1 aluno & $2,6 \%$ & 5 alunos \\
\multirow{2}{*}{ Tipo de conexão } & Discada & 8 alunos & $15,4 \%$ & 11 alunos & $29 \% \%$ & 19 alunos \\
& Banda Larga & 41 alunos & $78,9 \%$ & 26 alunos & $68,4 \%$ & 67 alunos \\
& Via Rádio & 3 alunos & $5,8 \%$ & 1 aluno & $2,6 \%$ & 4 alunos \\
\hline
\end{tabular}

Fonte: Do Autor

\section{Hábitos de Acesso à Internet}

Os hábitos de acesso foram medidos por meio de variáveis que solicitavam ao respondente estabelecer porcentagens dentre as opções de resposta, obtendo-se $100 \%$ pela soma de todas as opções.
A maior proporção dos acessos à Internet, em ambas as turmas, é realizada de suas residências. No período diurno, a maior parte dos acessos ocorre em casa, seguido pela faculdade. No que concerne ao período noturno, a maior parte dos acessos ocorre de casa, seguido pelo trabalho e pela faculdade. Ressalta-se que esta diferença 
de locais de acesso ocorre, pois os alunos do diurno estudam em período integral, ou seja, permanecem por todo o dia na faculdade e em maioria não trabalham. Por sua vez, grande parte dos alunos do período noturno trabalha, o que justifica que boa parte de seus acessos à Internet seja feita de seus locais de trabalho.

O Gráfico 1 apresenta a distribuição das porcentagens de acesso à Internet para as turmas. O gráfico revela que os alunos do período diurno acessam a Internet de casa, da faculdade e da casa de amigos com maior freqüência que os alunos do período noturno. Os alunos do período noturno, por sua vez, fazem seus acessos do trabalho em uma proporção maior que os alunos do diurno. Observa-se, também, que os alunos utilizam pouco Lan Houses para acessar a Internet. Esse aspecto é favorável à utilização da educação a distância, visto que para realizar atividades de interação e estudar on-line é necessário calma e concentração e nos ambientes Lan House talvez isto não seja possível.

Gráfico 1. Proporção de acessos à Internet

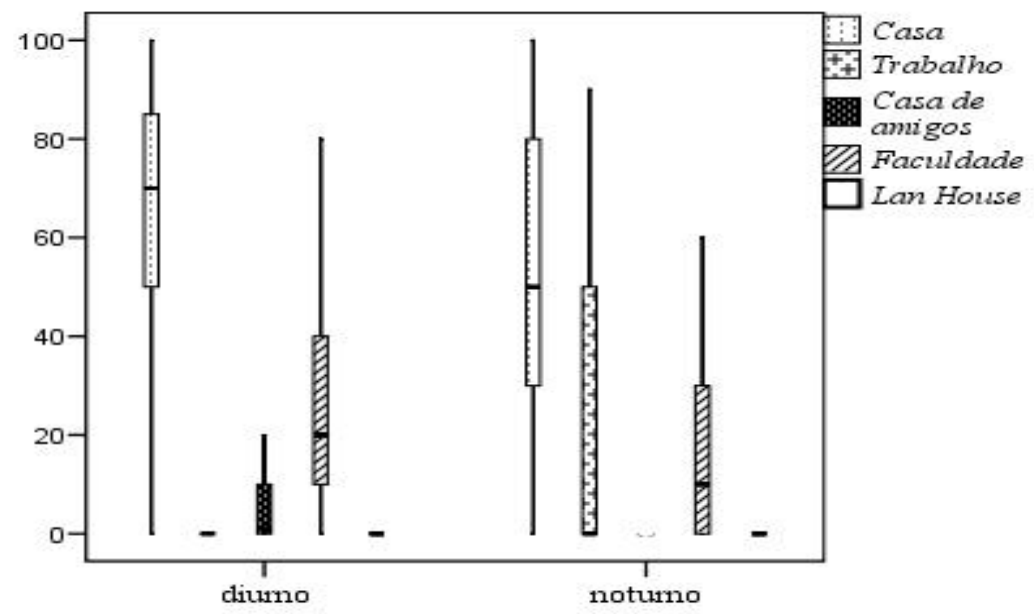

Fonte: Do Autor

A Internet é utilizada principalmente para realização de pesquisas, troca de e-mails, lazer e comunicação (via MSN, Skype etc.). Comparando-se os alunos dos períodos diurno e noturno, tem-se que os alunos do diurno acessam a Internet com objetivo de lazer e comunicação em uma proporção maior que os alunos do noturno. Os alunos do noturno realizam uma maior proporção de acessos com objetivo de realização de pesquisa e troca de e-mails que os alunos do diurno (Gráfico 2). 
Gráfico 2. Objetivos de acesso à Internet

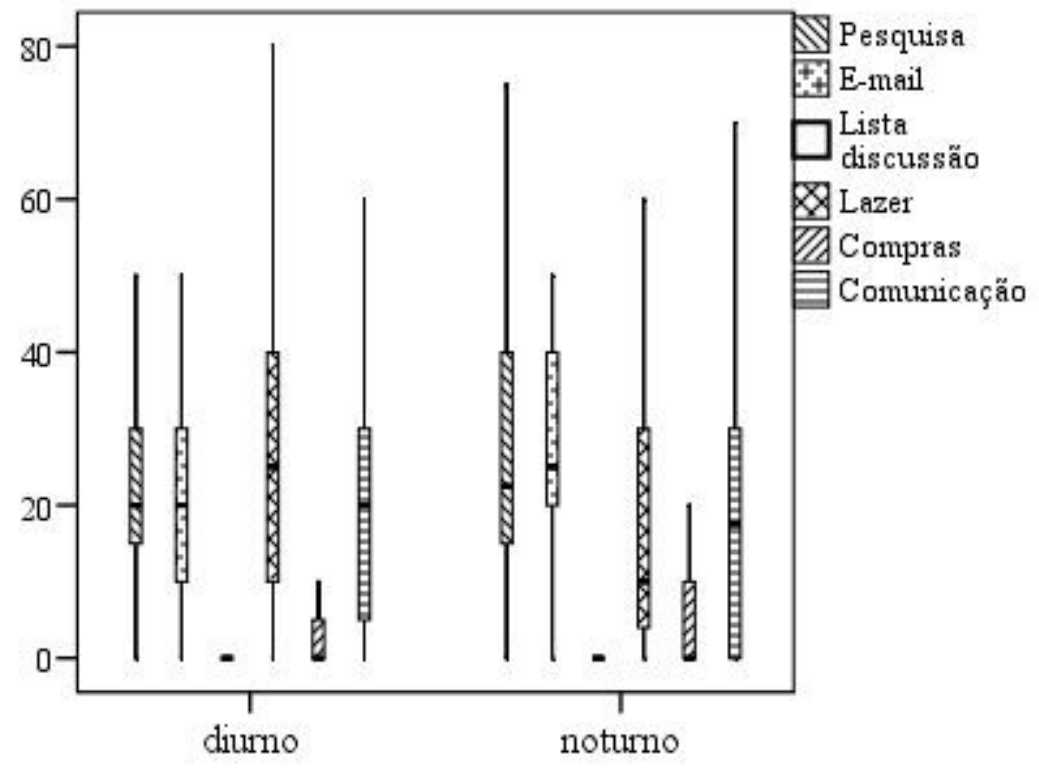

Fonte: Do Autor

Os alunos do período diurno realizam maior proporção de acessos no período da noite. Os alunos do período noturno realizam maior proporção de acessos durante a tarde, seguido pelo período da manhã. Isto provavelmente se deve aos horários das aulas destes alunos. Os alunos do diurno, tendo aulas de manhã e à tarde, realizam maior parte de acessos à Internet no período da noite, ou seja, fora do período de aula. Similarmente, os alunos do período noturno, tendo aulas à noite, fazem seus acessos à Internet fora dos horários de aula. Observa-se também que os alunos do período noturno, por trabalharem, realizam os acessos à Internet em horário de trabalho (Gráfico 3).

Gráfico 3. Distribuição dos períodos de acesso

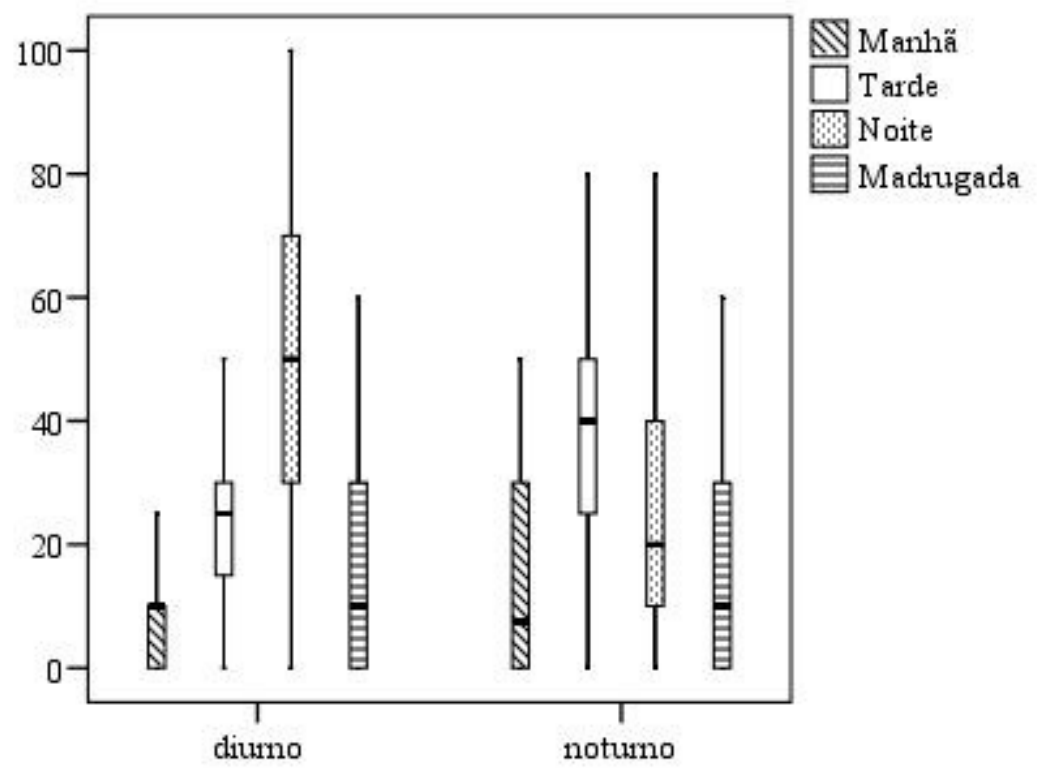

Fonte: Do Autor 
A maioria dos alunos, de ambos os períodos, utiliza o computador diariamente ou de quatro a seis vezes por semana. O Quadro 3 apresenta os dados de freqüência de uso do computador.

Quadro 3. Freqüência de uso do computador

\begin{tabular}{|lllllc}
\hline Hábitos de acesso & \multicolumn{3}{c}{ Período } & \multirow{2}{*}{ Total } \\
\cline { 2 - 4 } Freqüência de uso & \multicolumn{2}{c}{ Diurno } & \multicolumn{2}{c}{ Noturno } & \\
\hline Diariamente & 36 alunos & $63,2 \%$ & 26 alunos & $61,9 \%$ & 62 alunos \\
De 1 a 3 vezes por semana & 5 alunos & $8,8 \%$ & 2 alunos & $4,8 \%$ & 7 alunos \\
Entre 4 e 6 vezes por semana & 15 alunos & $26,3 \%$ & 9 alunos & $21,4 \%$ & 24 alunos \\
Somente durante a semana & 1 aluno & $1,8 \%$ & 5 alunos & $11,9 \%$ & 6 alunos \\
\hline
\end{tabular}

Fonte: Do Autor

Experiência com e-learning e ferramentas de análise de dados

Avaliando-se a experiência dos alunos com o e-learning, percebe-se que a maioria deles, no início da disciplina "Estatística Aplicada à Administração I", nunca havia participado de um curso on-line. No período noturno, há uma proporção maior de alunos que havia participado anteriormente de cursos na modalidade e-learning ( $16,7 \%$ dos alunos), enquanto no diurno esta porcentagem é de apenas $5,3 \%$ dos alunos.

Os alunos que já haviam realizado cursos online, tanto do período diurno quanto do noturno, os avaliaram apenas em relação aos materiais didáticos disponibilizados e à flexibilidade do curso, ou seja, a possibilidade de se realizarem as atividades do curso em horários definidos pelo aluno. Nenhum desses alunos mencionou fatores como interação e participação da tutoria como critérios para avaliação do curso.

Com relação à possível utilização de tecnologias educacionais na disciplina de Estatística, a maioria dos alunos considera esta possibilidade interessante e de auxílio na aprendizagem dos conceitos. Em ambos os períodos, há predominância de alunos que consideram que a utilização da educação a distância na disciplina agregaria valor ao curso (Quadro 4).

Quadro 4. Experiência com Educação a Distância

\begin{tabular}{|c|c|c|c|c|c|c|}
\hline & \multicolumn{3}{|c|}{ Diurno } & \multicolumn{2}{|c|}{ Noturno } & Total \\
\hline \multirow[t]{2}{*}{ Participou de curso on-line } & Sim & 3 alunos & $5,3 \%$ & 7 alunos & $16,7 \%$ & 10 alunos \\
\hline & Não & 54 alunos & $94,7 \%$ & 35 alunos & $83,3 \%$ & 89 alunos \\
\hline Uso da EAD na disciplina & Sim & 46 alunos & $80,7 \%$ & 33 alunos & $78,6 \%$ & 79 alunos \\
\hline $\begin{array}{l}\text { de Estatística pode auxiliar } \\
\text { na aprendizagem? }\end{array}$ & Não & 11 alunos & $19,3 \%$ & 9 alunos & $21,4 \%$ & 20 alunos \\
\hline
\end{tabular}

Fonte: Do Autor

O Quadro 5 expõe os aspectos favoráveis e desfavoráveis apresentados espontaneamente, em uma pergunta aberta, pelos alunos com relação ao possível uso da educação a distância na disciplina de
Estatística. O Quadro 5 expõe os aspectos favoráveis e desfavoráveis apresentados espontaneamente, em uma pergunta aberta, pelos alunos com relação ao possível uso da educação a distância na disciplina de Estatística. 
Quadro 5. Opinião dos alunos sobre o possível uso da EAD na disciplina de Estatística

\begin{tabular}{|lll|}
\hline Período & Favoráveis & Desfavoráveis \\
\hline Diurno & - Facilidade de acesso. & - A utilização de tecnologias é inadequada \\
& - Disponibilização de materiais. & para o ensino de Estatística. \\
& - Maneira inovadora de aprendizagem. & - Não conhecer a educação a distância. \\
& - Atendimento personalizado ao aluno. & - Falta de tempo para participar de \\
& - Dinamismo. & atividades de interação. \\
& - Interatividade. & \\
\hline Noturno & - Facilidade de acesso. & - A utilização de tecnologias éinadequada \\
& - Disponibilização de materiais. & para o ensino de Estatística. \\
& - Maneira inovadora de aprendizagem. & - Não apreciar materiais digitais. \\
& - Atendimento personalizado ao aluno. & - Não conhecer a educação a distância. \\
& - Dinamismo. & - Falta de tempo para participar de \\
& - Interatividade. & atividades de interação. \\
& - Oferece oportunidade de & - Isolamento da Educação a Distância. \\
& aprofundar conhecimentos. & \\
\hline
\end{tabular}

Fonte: Do Autor

Em geral, os alunos de ambos os períodos consideram que a utilização do e-learning facilita o acesso aos materiais do curso e o tornam mais dinâmico e interativo; além disso, acreditam ser uma maneira inovadora de ensino-aprendizagem, que, por meio das ferramentas de comunicação, oferece atendimento personalizado aos alunos. Em oposição, alguns alunos, que se mostraram desfavoráveis à utilização do e-learning na disciplina, e expuseram que esta modalidade de ensino é inadequada para cursos de Estatística, devido à sua natureza quantitativa. Ademais, alguns alunos se mostraram desfavoráveis por não conhecer a educação a distância, não apreciar materiais no formato digital e por considerar que esta modalidade acarreta em isolamento do aluno. Por fim, alguns alunos ainda acreditam que o uso do e-learning é inadequado, pois não possuem disponibilidade de tempo para participar de atividades de interação.

Os alunos fizeram uma auto-avaliação do seu grau de conhecimento a respeito de ferramentas da educação a distância e softwares estatísticos para análises de dados, com base em uma escala de 1 a 5 em que 1 indica nenhum conhecimento e 5 indica grande domínio da ferramenta. Considera-se a seguinte legenda para as notas: nota $<3,0$ pouco conhecimento, $3,0 \leq$ nota $<4,0$ conhecimento razoável e nota $\geq$ 4,0 bons conhecimentos. O Quadro 6 apresenta as estatísticas descritivas para cada ferramenta, sendo a sigla SPSS referente ao software Statistical Package for Social Sciences. 
Quadro 6. Estatísticas descritivas sobre o conhecimento de ferramentas do e-learning

\begin{tabular}{|lllll|}
\hline Conhecimentos sobre: & Diurno & Noturno & Geral \\
\hline Internet & Média & 3,9 & 4,1 & 4,0 \\
& Desvio-padrão & 0,7 & 0,8 & 0,7 \\
Excel & Coeficiente de variação & $18 \%$ & $19,5 \%$ & $17,5 \%$ \\
& Média & 2,7 & 3,2 & 2,9 \\
& Desvio-padrão & 0,8 & 0,8 & 0,8 \\
SPSS & Coeficiente de variação & $29,6 \%$ & $25 \%$ & $27,6 \%$ \\
& Média & 1,3 & 1,4 & 1,4 \\
\multirow{3}{*}{ Chat } & Desvio-padrão & 0,6 & 0,7 & 0,6 \\
& Coeficiente de variação & $46,2 \%$ & $50 \%$ & $42,9 \%$ \\
& Média & 3,6 & 3,7 & 3,6 \\
& Desvio-padrão & 0,9 & 1,1 & 1,0 \\
& Coeficiente de variação & $25 \%$ & $29,7 \%$ & $27,8 \%$ \\
& Média & 2,8 & 3,1 & 2,9 \\
& Desvio-padrão & 1,1 & 1,3 & 1,2 \\
& Coeficiente de variação & $39,3 \%$ & $42 \%$ & $41,4 \%$ \\
& Média & 4,3 & 4,5 & 4,4 \\
& Desvio-padrão & 0,6 & 0,7 & 0,6 \\
& Coeficiente de variação & $14 \%$ & $15,6 \%$ & $13,6 \%$ \\
\hline
\end{tabular}

Fonte: Do Autor

Em geral, os alunos possuem domínio razoável sobre as ferramentas de comunicação utilizadas na EAD (e-mail, chat e fórum), o que contribui para o sucesso de um curso on-line, tendo em vista que a comunicação é um dos fatores fundamentais dessa modalidade de ensino. Como se nota no quadro, os estudantes possuem bons conhecimentos da Internet e e-mail, poucos conhecimentos sobre SPSS, conhecimentos razoáveis sobre chat e fórum e Excel. Percebese que os alunos do curso noturno, em média, possuem maior domínio do Microsoft Excel que os alunos do diurno, e isso pode estar ligado ao fato de os alunos do noturno trabalharem, e o Excel ser utilizado por muitas empresas.

\section{Descrição da Disciplina}

A disciplina "Estatística Aplicada à Administração I", foi proposta como uma disciplina semipresencial, ou seja, com uma porcentagem da carga horária preenchida por aulas presenciais e uma porcentagem de horas preenchida por atividades a distância. Essa disciplina foi ministrada no primeiro semestre de 2007, no curso de Administração diurno e noturno da FEA-RP/USP. Tratando-se de uma disciplina de quatro créditos, há duas aulas de uma hora e quarenta minutos por semana. Esta disciplina, assim como as outras de Estatística, são presenciais, entretanto, no primeiro semestre de 2007, a disciplina "Estatística I" foi convertida em uma disciplina semipresencial. Algumas 
aulas e atividades presenciais passaram a ser ministradas a distância, por meio de um ambiente virtual de aprendizagem denominado LaViE.

A Portaria no. 4.059 do ano de 2004 que regulamenta a lei de Diretrizes e Bases no. 9.394/96 determina que as instituições de ensino superior podem incluir na grade curricular de seus cursos, disciplinas semipresenciais ou a distância, desde que a oferta de aulas a distância não ultrapasse $20 \%$ da carga horária total do curso (BRASIL, 2004). No caso da disciplina "Estatística I", a carga horária é de 30 aulas. Considerando-se esta proporção estabelecida pela Portaria no. 4.059/2004, pode-se incluir até seis aulas ministradas a distância. Dessa forma, as atividades ministradas on-line ocuparam apenas a carga horária de seis aulas.

Esta disciplina compreende seis módulos de conteúdo: testes de significância, testes de significância para médias, testes de significância para proporções, análise de variância, correlação e regressão. Definiu-se a utilização dos seguintes recursos: correio eletrônico, fórum, chat, textos digitais, tutoriais de uso do SPSS, glossário de conceitos estatísticos, exercícios entregues via site, exemplos de aplicação das técnicas, enquete, quadro de notas e espaço compartilhado de trabalho (os trabalhos práticos de todos os grupos de alunos foram disponibilizados nesse espaço para que outros grupos pudessem acessálos e avaliá-los). Apenas o fórum e a atividade no espaço compartilhado foram avaliados com notas de 0 a 10 e as outras atividades tiveram notas de participação, valendo até 0,5 ponto na média final do aluno.

O correio eletrônico foi um canal de comunicação permanente, entre professor/aluno, tutor/aluno e aluno/aluno, para que dúvidas e questionamentos pudessem ser enviados, sua utilização não foi obrigatória. Houve sessões semanais optativas de chat com a tutora, com duração de uma hora, às terças-feiras para o atendimento de dúvidas. Houve também enquetes semanais obrigatórias, com objetivo de forçar o estudante a acessar o portal pelo menos uma vez na semana. A participação no fórum foi obrigatória; assim, os alunos deveriam ler os exemplos práticos (artigos) para realizar sua participação. A leitura dos textos teóricos, tutoriais e glossário não foi obrigatória; porém, era necessária para que pudessem resolver os exercícios obrigatórios propostos e desenvolver os trabalhos práticos também obrigatórios. A atividade no espaço compartilhado também foi obrigatória e compreendia a avaliação dos trabalhos práticos desenvolvidos pelos estudantes. Cada grupo deveria avaliar o trabalho de outro grupo, isso exigia que tivessem domínio teórico da técnica; assim, os textos, tutoriais e glossário precisaram ser utilizados. O Quadro 7 apresenta como cada recurso foi utilizado na disciplina. 
Quadro 7. Utilização dos recursos do e-learning na disciplina

\begin{tabular}{|c|c|}
\hline Módulo & Atividades realizadas \\
\hline \multirow[t]{4}{*}{ Teste de hipóteses } & Leitura do texto \\
\hline & Utilização do glossário em caso de dúvidas conceituais \\
\hline & Realização de exercício \\
\hline & Disponibilização das notas no quadro de notas \\
\hline \multirow[t]{6}{*}{ Comparação envolvendo médias } & Leitura do texto \\
\hline & Utilização do glossário em caso de dúvidas conceituais \\
\hline & Utilização dos tutoriais para resolver um estudo de caso \\
\hline & Realização de exercício \\
\hline & Discutir sobre o estudo de caso no fórum \\
\hline & Disponibilização das notas no quadro de notas \\
\hline \multirow[t]{7}{*}{ Análise de Variância } & Leitura do texto \\
\hline & Utilização do glossário em caso de dúvidas conceituais \\
\hline & Utilização dos tutoriais para desenvolver o trabalho prático I \\
\hline & Realização de exercício \\
\hline & Análise de artigo para discussão no fórum \\
\hline & $\begin{array}{l}\text { Espaço compartilhado de trabalho: avaliação do trabalho I de } \\
\text { outro grupo }\end{array}$ \\
\hline & Disponibilização das notas no quadro de notas \\
\hline \multirow[t]{5}{*}{ Comparação envolvendo proporção } & Leitura do texto \\
\hline & Utilização do glossário em caso de dúvidas conceituais \\
\hline & Utilização dos tutoriais para resolver o exercício \\
\hline & Realização de exercício \\
\hline & Disponibilização das notas no quadro de notas \\
\hline \multirow[t]{5}{*}{ Análise de correlação } & Leitura do texto \\
\hline & Utilização do glossário em caso de dúvidas conceituais \\
\hline & Utilização dos tutoriais para desenvolver o trabalho práticoII \\
\hline & Realização de exercício \\
\hline & Disponibilização das notas no quadro de notas \\
\hline \multirow[t]{7}{*}{ Análise de regressão } & Leitura do texto \\
\hline & Utilização do glossário em caso de dúvidas conceituais \\
\hline & Utilização dos tutoriais para desenvolver o trabalho II \\
\hline & Realização de exercício \\
\hline & Análise de artigo para discussão no fórum \\
\hline & $\begin{array}{l}\text { Espaço compartilhado de trabalho: avaliação do trabalho II de } \\
\text { outro grupo }\end{array}$ \\
\hline & Disponibilização das notas no quadro de notas \\
\hline
\end{tabular}

Fonte: Do Autor 
Avaliação dos estudantes sobre a experiência na disciplina

$\mathrm{Na}$ opinião dos alunos, a educação a distância é uma forma inovadora de se estudar, e, por isso, no caso da disciplina semipresencial "Estatística Aplicada àAdministração I", mostrou-se interessante e estimulante. Os alunos consideraram a experiência com o ambiente virtual bastante interessante, pois flexibilizou a forma de estudo, rompendo as barreiras de tempo e espaço. O site foi considerado claro e organizado, com layout amigável e de fácil navegação. Dessa forma, foi possível interagir de forma dinâmica com a disciplina e, tendo em vista a obrigatoriedade da maioria das atividades, esta interação acabou forçando a aprendizagem.

$\mathrm{O}$ uso da Internet facilitou $\mathrm{o}$ acesso aos materiais do curso, que foram essenciais para o desenvolvimento adequado das atividades propostas, reduzindo a necessidade de uso de livros ou mesmo de auxílio do professor. A entrega de trabalhos pelo site flexibilizou as datas e horários de entrega, pois não precisavam ser no dia e horário da aula presencial, além de ter dispensado a entrega dos trabalhos em papel.

A utilização do LaViE estimulou a autonomia e a proatividade dos estudantes, reduzindo a responsabilidade atribuída ao professor pela aprendizagem do aluno.

Os alunos que participaram dos grupos focais consideraram que aprenderam mais estudando sozinhos pelo ambiente virtual do que pelas aulas presenciais. Consideraram até que as aulas presenciais foram superficiais em relação aos conteúdos disponíveis no ambiente. Alguns alunos sugeriram que, com o uso do LaViE, a disciplina poderia ter sua carga horária reduzida de quatro para dois créditos sem a ocorrência de perda na qualidade.

O incentivo ao uso de tecnologia foi considerado muito positivo, desde o uso do SPSS até as ferramentas da educação a distância e, principalmente, as discussões no ambiente digital (fórum e chat), pois serviram como uma experiência que poderá ser levada para a vida profissional.

A metodologia de apresentação da matéria em módulos auxiliou a criar uma lógica de aprendizagem. No entanto, cada um dos módulos foi disponibilizado ao longo da disciplina. Isto foi considerado inadequado, pois impediu que os alunos avançassem no estudo, seguindo seu próprio ritmo.

A maior dificuldade encontrada foi devida aos problemas com o servidor que deixaram o site fora do ar, o que comprometeu, de certa forma, a flexibilidade do curso, pois os alunos que não possuem estrutura de acesso em casa tiveram grandes inconvenientes. Ademais, a inexistência de alguns materiais, como exercícios resolvidos, links para outros sites, FAQ (frequently asked questions), mapa do site e a ocorrência de links sem conteúdo, gerou certa insatisfação.

Outro ponto mencionado foi a carga excessiva de atividades obrigatórias semanais que consumiram muito tempo para execução. A possibilidade de ter diversas notas provenientes dessas atividades foi considerada algo positivo, pois reduziu a ansiedade com relação ao desempenho nas provas. Entretanto, a carga de atividades foi motivo de constantes queixas.

Alguns alunos ressaltaram a dificuldade em se aprender estatística a distância, salientando que, se tivessem opção, não teriam escolhido a modalidade semipresencial, por receio de não conseguirem acompanhar a disciplina.

Os alunos avaliaram a tutoria de forma satisfatória. Criaram empatia com a tutora, considerando-a atenciosa tanto no esclarecimento de dúvidas quanto ao entrar em contato com os alunos que deixaram de participar de alguma atividade ou que passaram um tempo prolongado sem acessar o ambiente virtual.

$\mathrm{O}$ atendimento aos alunos foi considerado personalizado, facilmente acessível e com tempo 
rápido de resposta às dúvidas. Além disso, consideraram as instruções oferecidas pela tutora muito claras e úteis, pois evidenciavam exatamente o que se esperava como desempenho do aluno.

Alguns alunos atribuíram, em parte, o sucesso da utilização do LaViE nesta disciplina à participação da tutora e à sua competência tanto na gestão das atividades on-line quanto no domínio dos conteúdos ministrados.

Em oposição, consideraram excessiva a quantidade de e-mails enviados pela tutora, o que levou a não-leitura de boa parte deles. Além disso, consideraram importante que a tutora participasse também das aulas presenciais, pois apenas virtualmente o contato torna-se muito impessoal.

Sob a ótica do gerenciamento do curso, o LaViE apresenta muitas deficiências, algumas delas mencionadas pelos próprios alunos, como a dificuldade de administração de participação nas enquetes e a falta de flexibilidade da ferramenta fórum.

O ambiente não oferece relatórios de acesso específicos para cada turma. Armazena indiscriminadamente os acessos efetuados em determinado período, seja por aluno matriculado na disciplina, usuário inscrito no LaViE ou mesmo um usuário não inscrito. Desta maneira, o acompanhamento dos alunos torna-se complexo e oneroso, consumindo tempo excessivo da tutoria.

Ressalta-se que os fóruns foram realizados com as duas turmas concomitantemente, pois não há a possibilidade de se criarem dois fóruns simultaneamente e nem de restringir o acesso de usuários a este recurso. Analogamente, a enquete permite o voto de qualquer usuário, mesmo não matriculado na disciplina.

Além disso, houve problemas técnicos graves que prejudicaram o andamento do curso, como o não-funcionamento da ferramenta correio eletrônico do site e o não-armazenamento de alguns arquivos enviados pelos estudantes.
Houve problemas com a eletricidade e com a rede de Internet da universidade que danificaram peças do servidor onde estava instalado o ambiente, o que deixou o site fora do ar por alguns dias e trouxe muitos inconvenientes.

As dificuldades listadas tornam o LaViE um ambiente ineficiente para ministrar cursos on-line. Apesar de seu layout amigável e desenhado para o ensino de Estatística, suas deficiências com relação ao armazenamento de dados tornam seu pleno uso inadequado. Dessa forma, recomenda-se a sua utilização apenas como apoio ao ensino presencial, ou seja, para disponibilização de material e notas.

\section{Conclusão}

Tendo em vista as dificuldades observadas no ensino-aprendizagem de Estatística Aplicada à Administração, iniciativas que tentem flexibilizar o ensino desta disciplina, ou que possam aproximar teoria e prática, são muito relevantes.

Este artigo estudou uma disciplina semipresencial de Estatística Aplicada à Administração com 20\% de sua carga horária preenchida com atividades on-line. Estas atividades compreenderam desde a leitura de materiais on-line até a interação síncrona e assíncrona via chat e fórum e e-mail, respectivamente.

A literatura afirma que a estrutura de acesso do aluno é de fundamental importância para o sucesso de um curso on-line. Por essa razão, durante a primeira aula foram coletados dados sobre o perfil do aluno. Observou-se que a maioria dos estudantes possuía computadores em suas residências, com acesso à Internet, em maior parte com conexão banda larga. Além disso, os alunos que não possuíam estrutura tão satisfatória poderiam utilizar os laboratórios de informática disponíveis na faculdade.

Os estudantes, em maioria, utilizam o computador diariamente e possuem bons conhecimentos sobre Internet e e-mail e conhecimentos razoáveis sobre ferramentas de interação como fórum e chat. 
Desta forma, todas estas características poderiam auxiliar na experiência do aluno com as atividades a distância.

Em oposição, observou-se que poucos alunos haviam participado anteriormente de cursos a distância. Porém, a maioria considerou que o possível uso das tecnologias educacionais poderia auxiliar na aprendizagem. Apontaram como possíveis pontos favoráveis na utilização da EAD aspectos que resumem os objetivos da educação a distância: atendimento personalizado ao aluno, flexibilidade, dinamismo e interatividade. Por outro lado, apontaram como possíveis pontos desfavoráveis o isolamento da EAD e sua crença de que não seja adequada ao ensino de Estatística. Esses aspectos desfavoráveis poderiam influenciar negativamente suas atitudes em relação à disciplina. Assim, a tutoria esteve bastante presente e as ferramentas de interação foram amplamente utilizadas para que estas percepções ruins fossem desfeitas.

Ao final do curso, os grupos focais realizados revelaram que a experiência para o aluno, em geral foi positiva, estimulando a autonomia e a proatividade. Apontaram que a flexibilidade de horários de estudo e de entrega dos trabalhos foi bastante apreciada. Os estudantes consideraram positivo o uso das ferramentas de interação e dos softwares estatísticos, podendo aplicar os conhecimentos adquiridos não apenas na disciplina, mas também na vida profissional.

A qualidade e organização dos materiais contribuíram para que esta experiência fosse bem sucedida. Além disso, a presença constante da tutoria, ao orientar atividades, esclarecer expectativas de desempenho e sanar dúvidas, reduziu a sensação de isolamento provocada pela EAD e a ansiedade dos estudantes em relação ao curso, pois tiveram acesso constante à tutora sempre que necessitaram.

Por outro lado, apesar de os alunos possuírem estrutura física adequada à realização de um curso on-line, os problemas técnicos enfrentados com o ambiente virtual oneraram o curso e causaram certa insatisfação. Além desses problemas, características do ambiente, tais como a dificuldade em gerenciar os acessos e a interface ruim de algumas ferramentas, como o fórum, tornaram a atividade de tutoria bastante complexa.

Dessa forma, a experiência foi bem sucedida e positivamente avaliada pelos estudantes, o que mostra que as ferramentas da educação a distância podem ser utilizadas efetivamente no ensino de Estatística para Administração. Entretanto, é necessário que o curso seja bem planejado e as atividades bem desenhadas de acordo com o objetivo do curso. O perfil dos estudantes deve ser avaliado para que as atividades realizadas sejam coerentes com suas possibilidades; por exemplo, se a maioria dos alunos não possui conexão banda larga, torna-se inadequada a organização de discussões síncronas no chat. Os materiais devem ser desenvolvidos de acordo com os conteúdos do curso; porém, devem ser apropriados para o estudo em meio digital, ou seja, o formato dos materiais deve ser repensado para esta realidade.

A escolha do ambiente virtual adequado é muito importante, pois pode tornar mais ou menos complexa a atividade da tutoria e pode impactar significativamente na satisfação do aluno.

A acessibilidade do tutor é fundamental, pois ele mantém contato constante com o aluno, atendendo às suas necessidades e observando seu comportamento, de forma que falhas podem ser identificadas e corrigidas ainda ao longo do curso. No entanto, verifica-se que a tutoria é bastante trabalhosa e consome tempo; portanto, pode ser inviável que o próprio professor da disciplina acumule as duas funções, sendo ideal a presença de um terceiro, capacitado tanto no uso da EAD quanto nos conteúdos do curso.

Por fim, observa-se que a obrigatoriedade de participação nas atividades com atribuição de nota torna a utilização da EAD mais efetiva, pois conforme os alunos declararam, se não houvesse essa obrigatoriedade, muitos deles não teriam 
acessado o ambiente e participado das atividades (devido à sua percepção prévia de que a EAD é inadequada ao ensino de Estatística), experiência esta que ao final foi considerada positiva.

\section{Referências}

BARBOUR, R. S.; KITZINGER, J. Developing focus group research: politics, theory and practice. Thousand Oaks: Sage, 1999.

BEM-ZVI, D. Toward understanding the role of technological tools in statistical learning. Mathematical Thinking and Learning, Mahwah, v. 2, n. 1/2, p. 127-155, 2000.

BORBA, S. F.; AYROSA, P. P. S. Uma experiência da aplicação da educação a distância via internet como ferramenta complementar a cursos presenciais. In: CONGRESSO INTERNACIONAL DE EDUCAÇÃO A DISTÂNCIA, 8., 2001, Brasília. Anais... Brasília: Associação Brasileira de Educação a Distância, 2001. Disponível em: $<$ http://www.abed.org.br $>$. Acesso em: 4 fev. 2007.

BRASIL. Portaria $\mathrm{n}^{\circ} .4 .059$ de 10 de dezembro de 2004. Regulamenta o Art. 81 da LBD (Lei no. 9.394/96) e o Art. $1^{\circ}$ do Decreto $n^{\circ}$ 2.494/98. Diário Oficial da União, Brasília, 13 dez. 2004. Disponível em: <http://portal. mec.gov.br/sesu/arquivos/pdf/nova/acs_portaria4059 .pdf>. Acesso em: 27 fev. 2007.

CARVALHO NETO, S.; ZWICKER, R.; CAMPANHOL, E. M. Ensino on-line na graduação de Administração: um estudo de prós, contras e da possibilidade de implantação de um ambiente virtual de aprendizagem em uma IES do estado de São Paulo. In: ENCONTRO ASSOCIAÇÃO NACIONAL DE PÓS-GRADUAÇÃO E PESQUISA EM ADMINISTRAÇÃO, 30., 2006, Salvador. Anais... Salvador: Associação Nacional de Pós-Graduação e Pesquisa em Administração, 2006. p. 1-16.

CARVALHO, C. Literacia estatística. In: SEMINÁRIO DE ENSINO DE MATEMÁTICA, 1., 2003, Campinas. Anais... Campinas: COLE, 2003. Disponível em: $<$ http:// cie.fc.ul.pt/membros/ccarvalho/doc8.pdf $>$. Acesso em: 23 maio 2006.

DENNEN, V. P. From message posting to learning dialogues: factors affecting learner participation in asynchronous discussion. Distance Education, London, v. 26, n. 1, p. 127-148, May 2005.

FILATRO, A. Design instrucional contextualizado: educação e tecnologia. São Paulo: SENAC, 2004.

FILATRO, A.; PICONEZ, S. C. B. Design instrucional contextualizado. In: CONGRESSO INTERNACIONAL DE EDUCAÇÃO A DISTÂNCIA, 11., 2004, Salvador. Anais... Salvador: Associação Brasileira de Educação a Distância, 2004. Disponível em: $<$ http://www.abed.org. br>. Acesso em: 29 jan. 2007.

FREITAS, A. S. de; BERTRAND, H. Ensino a distância no Brasil: avaliação de uma parceria universidade-empresa. In: ENCONTRO ASSOCIAÇÃO NACIONAL DE PÓS-GRADUAÇÃO E PESQUISA EM ADMINISTRAÇÃO, 30., 2006, Salvador. Anais... Salvador: Associação Nacional de Pós-Graduação e Pesquisa em Administração, 2006. p. 1-16.

GELMAN, A. A course on teaching statistics at the university level. The American Statistician, Alexandria, v. 59, n. 1, p. 4-7, Feb. 2005.

GIL, A. C. Como elaborar projetos de pesquisa. 4. ed. São Paulo: Atlas, 2002.

KOSZALKA, T. A.; GANESAN, R. Designing online courses: a taxonomy to guide strategic use of features available in course management systems (CMS) in distance education. Distance Education, London, v. 25, n. 2, p. 243-256, Oct. 2004.

KRUEGER, R. A.; CASEY, M. A. Focus group: a practical guide for applied research. 3. ed. Thousand Oaks: Sage, 2000.

LAAT, M. D.; LALLY, V. It's not so easy: researching the complexity of emergent participant roles and awareness in asynchronous networked learning discussions. Journal of Computer Assisted Learning, Osney Mead, v. 20, p. 165-171, 2004.

MARTINS, G. A. Estudo de caso: uma estratégia de pesquisa. São Paulo: Atlas, 2006.

MAXIMIANO, A. C. A.; JACOBSOHN L. V.; KUNIYONSHI, M. Gestão de projetos de e-learning: planejamento de uma disciplina on-line do curso de Administração. In: PARTERNSHIP IN GLOBAL LEARNING CONFERENCE, 3., 2005, São Paulo. Anais... São Paulo: The Partnership in Global Learning, 2005. p. 1-15.

MILAGRE, R. A. Estatística: uma proposta de ensino para os cursos de Administração de Empresas. 2001. 160 f. Dissertação (Mestrado em Engenharia de Produção) Programa de Pós-graduação em Engenharia de Produção, Universidade Federal de Santa Catarina, Florianópolis. Disponível em: <http://teses.eps.ufsc.br/tese.asp>. Acesso em: 26 jan. 2007.

NOLAN, D.; SPEED, T. P. Teaching statistics theory through applications. The American Statistician, Alexandria, v. 53, n. 4, p. 370-375, Nov. 1999. 
PAN, W.; TANG, M. Examining the effectiveness of innovative instructional methods on reducing statistics anxiety for graduate students in social sciences. Journal of Instructional Psychology, Mobile, v. 31, n. 2, p. 149159, 2004.

PAN, W. S. The challenges of teaching statistics in the current techonology environment. Journal of American Academy of Business, Cambridge, v. 3, p. 351-355, Sept. 2003.

PETOCZ, P.; REID, A. Something strange and useless: service students' conceptions of statistics, learning statistics and using statistics in their future profession. International Journal of Mathematical Education in Science and Technology, London, v. 36, n. 7, p. 789-800, 2005.

PINHEIRO, M. A. Estratégias para o design instrucional de cursos pela internet: um estudo de caso. 2002. 82 f. Dissertação (Mestrado em Engenharia de Produção) - Programa de Pós-graduação em Engenharia de Produção,Universidade Federal de Santa Catarina, Florianópolis. Disponível em: <http://teses.eps.ufsc.br/ tese.asp>. Acesso em: 25 jan. 2007.

RAMOS, B. S. S. Interações mediadas pela tecnologia digital: a experiência do fórum virtual em um projeto de educação a distância. In: CONGRESSO INTERNACIONAL DE EDUCAÇÃO A DISTÂNCIA, 12., 2005, Florianópolis. Anais... Florianópolis: Associação Brasileira de Educação a Distância, 2005. Disponível em: <http://www.abed.org.br>. Acesso em: 29 jan. 2007.

RICHARDSON, R. J. Pesquisa social: métodos e técnicas. 3. ed. São Paulo: Atlas, 1999.

ROSENBERG, M. J. E-learning: strategies for delivering knowledge in the digital age. New York: McGraw-Hill, 2001.

STORK, D. Teaching statistics with survey data: a pedagogical innovation in support of student learning. Journal of Education for Business, Washington, p. 335339, July/Aug. 2003.

VIEIRA, F. M. S. Considerações teórico-metodológicas para elaboração e realização de cursos virtuais. In: CONGRESSO INTERNACIONAL DE EDUCAÇÃO A DISTÂNCIA, 8., 2001, Brasília. Anais... Brasília: Associação Brasileira de Educação a Distância, 2001. Disponível em: $<$ http://www.abed.org.br>. Acesso em: 4 fev. 2007.

YIN, R. K. Estudo de caso: planejamento e métodos. 3. ed. Porto Alegre: Bookman, 2005.
Recebido em: agosto 2009

Aceito em: março 2010 
